\title{
ARCHITECTURE AND LANDSCAPE DESIGN FOR BEIKANZI VILLAGE IN CHINA: AN INVESTIGATION OF HUMAN SETTLEMENT AND ENVIRONMENT
}

\author{
${ }^{1}$ Dapeng ZHAO, ${ }^{2}$ Balint BACHMANN, ${ }^{3}$ Tie WANG \\ ${ }^{1}$ Marcel Breuer Doctoral School, Faculty of Engineering and Information Technology \\ University of Pécs, Boszorkány u. 2, H-7624 Pécs, Hungary, e-mail: 463001773@qq.com \\ ${ }^{2}$ Institute of Architecture, Faculty of Engineering and Information Technology, University of \\ Pécs, Boszorkány u. 2, H-7624 Pécs, Hungary, e-mail: bachmannbalint.mik@gmail.com \\ ${ }^{3}$ Department of Architecture Design, China Central Academy of Fine Arts, Huajiadi south \\ street No.8, Chaoyang, Beijing, China, e-mail: wtgzs@163.com
}

Received 11 December 2017; accepted 7 February 2018

\begin{abstract}
The vast rural areas, which contain historical, cultural heritage and natural resources areas are the root for the stability of China and the foundation of the Chinese nation. However, excessive urban development and construction has affected these smaller rural villages, which were left behind due to China's rapid economy. This is a design study of the 'Beautiful Village' Project, initiated by the local government, in order to demonstrate an opportunity to redesign the rural areas. This paper exhibits the experiences and impressions of the architects from China Central Academy of Fine Arts who took part in the architecture design for the villages. In order to achieve this, a series of investigation and analysis was done by the architects to reveal the present situation of the villages in China. Additionally, the active participation of the villagers is crucial in the successful re-development of the area. The main objective of this paper is to therefore identify the difficulties and problems encountered by the village and to propose a counter solution in order to design a better living condition for the rural areas of China.
\end{abstract}

Keywords: Rural development, Urban-rural integration, Ural living conditions, Humanization

\section{Introduction}

Since the dawn of the $20^{\text {th }}$ century, China has seen massive economic development and construction developments have been in the rise. During this time that major construction of Chinese cities increased in growth never before seen in the history of the country. Because of this, most of the developments in the rural areas remain ignored in spite of its huge potential in the availability of human and natural resources. The Chinese government has been prioritizing the growth of major cities while overlooking 
the huge potential of the countryside [1]. In the turn of the $21^{\text {st }}$ century, however, the Chinese government is now planning to focus its development in the rural areas [2]. The government would like to change the unfair balance of development between urban and rural areas. Since 2005, the rehabilitation of the rural areas is now the foremost objective of the Chinese government. In 2013, the government has therefore initiated the 'Beautiful Villages', spearheaded by the Ministry of Agriculture. The proposed ten models for the 'Beautiful Project' were therefore publicized in 2014. This project is a multidisciplinary re-development of the rural areas of China that encompasses architecture, agronomy, economics, ecology and sociology, among others. To date, the 'Beautiful Village' project is therefore a comprehensive and highly coordinated rural project imitated by the Chinese government. In this paper, one of the author, who is a member of the Institute of Architecture design, China Central Academy of Fine Arts, documents his experiences and knowledge gained in the project from an architectural point of view. The project was initiated in the town of Xinglong, Chengde City, part of the Hebei province in China. Additionally, the methodology and concept of the schematic designs will be presented. The knowledge gained in this study will therefore be vital for other architectural institutions in the process of re-development of the rural areas, of which sometimes were being neglected due to the demands of massive urban growth.

\subsection{Profile of the village}

Xinglong is located in the northeast part of Hebei province and it is the southernmost town in Chengde, near the northern part of the Great Wall. It is a mountainous area with a huge vertical variation of temperatures. The area is about 3123 square kilometers but $84 \%$ of the area is occupied by rough mountain terrain. The present population is estimated to be around 330,000 in the year of 2016. Xinglong has a mild semi-humid temperature and the average elevation is around 1000 meters from the sea level. The annual average temperature is between $6.5^{\circ} \mathrm{C} 10.3^{\circ} \mathrm{C}[3]$. Under the guidance of the provincial policy of Hebei, Xinglong was chosen as one of the first batch of demonstration units because of its advantages to focus on the development of rural tourism. Availing of this opportunity, a decision had been made by the local government to develop a series of tourism villages and make a complete tourism industry chain to improve the economy of the whole territory. In this paper, the author was responsible for the architecture and landscape design of Beikanzi village, which is 20 kilometers west of Xinglong town center. Beikanzi is a typical mountainous village in Xinglong. The area of the village is about 6.18 square meters and the population is 1125 in 2016.

\subsection{Profile of the houses}

Like hundreds of northern villages in Northern China, the houses of the Beikanzi village are constructed from gray or red bricks (mixed with local granite) with gray tile roof (Fig. 1).The typical scene of the village are composed of these simple and concise architectural elements. Beikanzi lacks the cultural individuality when compared to other villages. Most family houses of the village are located in a relatively flat terrain and the 
typical layout of the local traditional houses is located in north, facing south. Inside the yard, the main house is in the northernmost part and the other three sides are enclosed by walls higher than the height of an average man. The main gate is in the south wall. Partition walls are shared among the neighbors, and one living unit is constituted by the extension of many houses to the direction of east and west. Depending on the condition of the terrain condition, an additional unit in the north or south direction will be built when the former one reaches the limitation, with a 2-3 meters road interval between each other, thus forming the traditional street scale. Presently, more concrete boxes with ceramic tile facade are constructed which now become the new building style among the community [4]. As these western styles are getting popular, the declining traditional village scene is inconceivable. Meanwhile, in the past ten years, a large number of 2 or 3 story houses are built due to the improvement of economic conditions and the demand of living of the locals. Therefore, there is a tremendous transformation in the village in terms of architecture and landscape aspect.

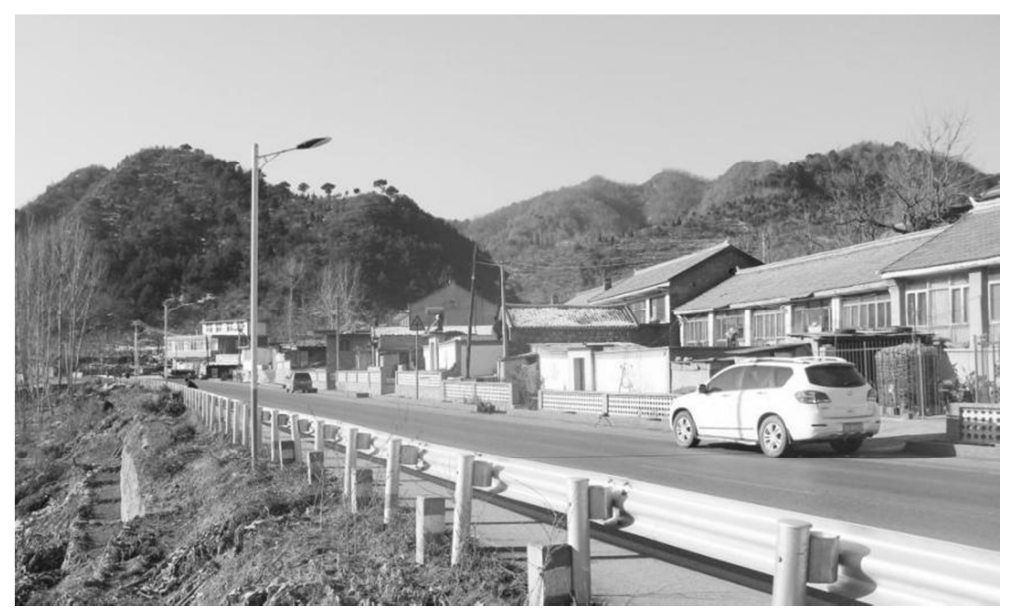

Fig. 1. The typical view of Beikanzi village

\subsection{Existing condition of the village}

The Qingshui River and most tracts of farmland and forestry belong to the village are in the south part of the settlement. Beikanzi is divided into two parts by the provincial road, of which the villagers need to pass through frequently for their daily routine. The road is a potential safety hazard for the local people because of the number of automobile traffic. What is more, the road is adjacent to the first row houses, with no clear defined buffer zone. Additionally, due to long-term lag of rural development, rural infrastructure construction is seriously inadequate. It has brought great inconvenience for the daily life of the villagers, such as lacking of sewer system, heating system, gas system, recycling system, among others. Finally, public spaces are almost non-existent and only the parking areas are used as a communal space. 


\section{Design methodologies}

One of the objectives of the project proposed by the Chinese local government is a new type of village, which is livable, dynamic and eye-catching. Therefore, in the field of architecture design, the demand will be concentrated on solid structure, reasonable function, affordable, the use of simple construction techniques, comfortable environment and development in form. In the field of village planning, the requirement will be unimpeded traffic and conservation land-use, among others. Meanwhile, a comprehensive analysis should be implemented for the aspects of courtyards combination, streets connections, and pavements, construction materials, building colors, architectural decorations, component structures, municipal facilities, shop signs, information indicators and street furniture [5], [6]. Therefore, after the discussion between the design team, local government and villagers, it was decided that the village development could not be limited by the so-called traditional and historical factors and the architecture design could not be confined by the past forms. A rigorous classification of the buildings inside the project area was done by the design team. Among the aspects to be considered are the structural integrity, the appearance of morphological characteristics and the definition of property rights. With the application of typology, the village houses were divided into three parts, which are the preservation, refurbishment and demolition of the structures. These schemes can qualify the requirements of tourism and further developments could be drawn up by respecting original village layout, settlement texture, architectural rhythm and form [7]. A variety of multiple, flexible conceptions should be considered according to the diversity of economic situation, habits, business and aesthetics among each family instead of homogenization.

\subsection{Design survey}

In order to properly meet the needs of the members of the community, the design team reached out to the members of the villagers. Survey questionnaires were being sent in order to be able to identify and apprehend their perception about the proposed project. With the assistance from the local village collective, the recovery rate for the survey was over $95 \%$. By using this technique, the research team received important information for the design. Among them are the opinions about the governmental program, the expected village industry, the urgent upgrading, the expected financial investment, architecture style and the interpretation of the connection between local tradition and present-day development.

It is an essential work to acquaint the traditional local habits and customs related to agrarian economy. Appropriate facilities will be considered as a part of architecture and landscape design for the purpose of inheriting the agricultural culture and enhancing the interaction between village hosts and guests to develop the tourism based on agricultural industry [8].

In the vast rural areas, it is a cruel fact that the traditional construction methods that contain individual aesthetic value are vanishing. Collection and arrangement of these disappearing elements should be operated by the design team and then create the 
combination among traditional material, technology and modern conception, keeping historical memories while developing [8], [9].

\subsection{Proposed solutions}

The proposed architectural style is a reflection of the local economy, technology and culture for a certain period of time [10], [11]. The architectural styles of most of the Chinese villages are far behind the modern times due to the backward development in the countryside. As soon as the opportunity appears, the organic rural development is limited by the current national conditions. The rural construction sites are controlled due to the scant arable land for the huge population. According to the regulation of Hebei province, the maximum area of rural house site is 233 square meters which is slightly lesser than usual. This size is not comfortable for two to three generations of families living together in a one story house, thus a vertical expansion is one of solutions. Meanwhile, the height limitation should be considered in case of unrestrained construction, matching the scale of the existing 2-3 level houses. Aside from the interior spaces, the situation caused by the provincial road crossing the village is also a problem that needs to be addressed by the designers. In addition, in order to increase the safety of the villagers, landscape and administration facilities can be arranged along the road with different pavement texture to emphasize the settlement zone when the drivers are passing. Beside these, it is also necessary to cooperate with the municipal department to arrange the location of different kinds of waste pipes. Guidance and assistance should be provided during the construction on the basis of municipal pipe network. Finally, it is an important issue to improve the utilization rate of public buildings in the village in order to raise the quality of life of the villagers. For this reason, the administrative structures such as the village collective building can be transformed into a complex facility for village activities and tourism.

\section{Proposed recommendations}

The architecture and landscape design documents (Fig. 2) for Beikanzi village based on the stated methodology had been submitted to the local government for recognition. It has been one and half years since the beginning of the proposed 'Beautiful Village' project, and the construction is already in process. The communication between the local government and the design team is vital and must be continued in order for the project to be successful.

\section{Conclusion}

More research achievements and renewed conceptions will be accomplished with the further study of villages and wider cooperation with foreign colleagues. As a result, Beikanzi will be shaped as a landmark of new Chinese style villages with the optimal scheme and the conformance of development. 


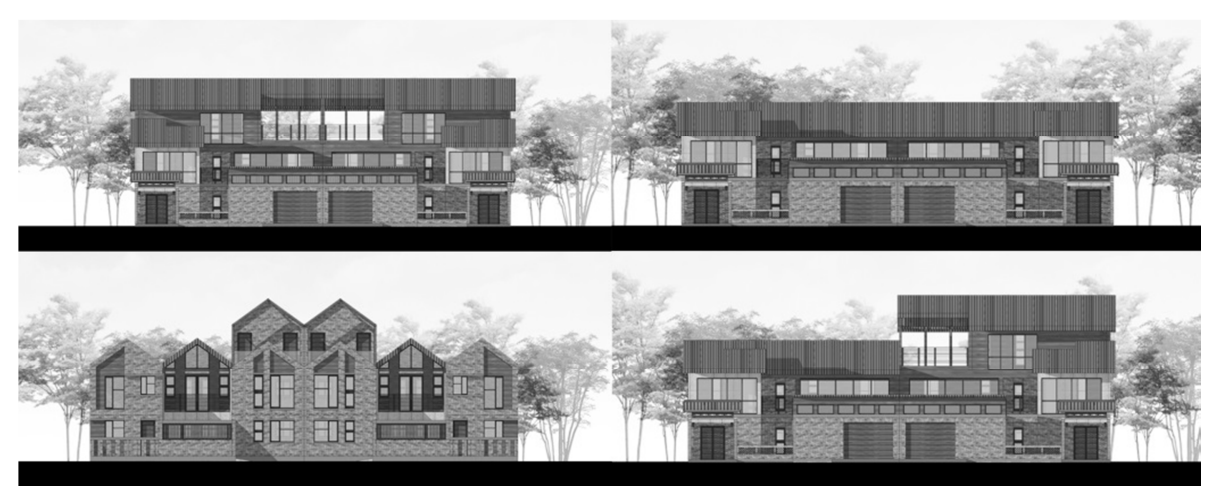

Fig. 2. Some suggested solutions for the further construction

\section{Acknowledgements}

The preparation of this paper was supported by Marcel Breuer Doctoral School, University of Pecs. The project was supported by Xionglong government and Institute of Architecture Design, China Central Academy of Fine Arts.

\section{References}

[1] Kan K. The transformation of the village collective in urbanizing China: A historical institutional analysis, Journal of Rural Studies, Vol. 47, Part B, 2016, pp. 588-600.

[2] GuoZ., Sun L. The planning, development and management of tourism: The case of Dangjia, an ancient village in China, Tourism Management, Vol. 56, 2016, pp. 52-62.

[3] Shan Z., Qingsheng W. Xinglong County Gazetteers, Xinhua Publishing House, ISBN: 7501149828, 2004.

[4] XiaoyuL., Beisi J. Living sustainably: Transformation of the built environment in Xiaqiao village, China, Procedia Engineering, Vol. 142, 2016, pp. 48-55.

[5] Jiaping H. Study on the conservation planning technology of historical and cultural small towns and villages, South China University of Technology, 2014.

[6] Jacobs J. The death and life of great American cities, Randon House Trade Publishing, 2006.

[7] Zhang T., Hiroatsu F., Hu Q, Analysis on traditional Gully Village's sustainable development methods in Gully Region of Loess Plateau, Procedia - Social and Behavioral Sciences, Vol. 216, 2016, pp. 87-96.

[8] Balan M., Burghelea C. Rural tourism and its implication in the development of the Fundata Village, Procedia - Social and Behavioral Sciences, Vol. 188, 2015, pp. 276-281.

[9] Jing Gao, Bihu Wu. Revitalizing traditional villages through rural tourism: A case study of Yuanjia Village, Shaanxi Province, China, Tourism Management, Vol. 63, 2017, pp. 223-233.

[10] Ravina D. V., Shih R. R. L., Medvegy G. Community architecture: the use of participatory design in the development of community housing project in the Philippines, Pollack Periodica, Vol. 13, No. 2, 2018, pp. 207-218.

[11] Hajnaj D., Hoxha O. Wood in the urban environment in Albania, Pollack Periodica, Vol. 12, No. 3, 2017, pp. 117-128. 